\title{
A statistical approach for the production of thermostable and alklophilic alpha-amylase from Bacillus amyloliquefaciens KCP2 under solid-state fermentation
}

\author{
Vimal S. Prajapati $\cdot$ Ujjval B. Trivedi • \\ Kamlesh C. Patel
}

Received: 12 February 2014/Accepted: 25 March 2014/Published online: 11 April 2014

(C) The Author(s) 2014. This article is published with open access at Springerlink.com

\begin{abstract}
The bacterial strain producing thermostable, alklophilic alpha-amylase was identified as Bacillus amyloliquefaciens KCP2 using 16S rDNA gene sequencing data (NCBI Accession No: KF112071). Medium components were optimized through the statistical approach for the synthesis of alpha-amylase by the organism under solid-state fermentation using wheat bran as the substrate. The medium components influencing the enzyme production were identified using a two-level fractional factorial Plackett-Burman design. Among the various variables screened, starch, ammonium sulphate and calcium chloride were found to be most significant medium components. The optimum levels of these significant parameters were determined employing the response surface Central Composite design which significantly increased the enzyme production with the supplementation of starch $0.01 \mathrm{~g}$, ammonium sulphate $0.2 \mathrm{~g}$ and $5 \mathrm{mM}$ calcium chloride in the production medium. Temperature and $\mathrm{pH}$ stability of the alpha-amylase suggested its wide application in the food and pharmaceutical industries.
\end{abstract}

Keywords Thermostable alpha-amylase . Plackett-Burman design · Response surface methodology $\cdot$ Solid-state fermentation . Bacillus amyloliquefaciens KCP2

V. S. Prajapati · U. B. Trivedi · K. C. Patel $(\bowtie)$ BRD School of Biosciences, Sardar Patel University, Sardar Patel Maidan, Vadtal Road, Satellite Campus, Post Box No. 39, Vallabh Vidyanagar 388-120, Gujarat, India

e-mail: comless@yahoo.com

\section{Introduction}

Amylases find potential application in number of industrial processes such as bread making, brewing, starch processing, pharmacy, textile industries. Alpha-amylase is an extracellular enzyme that randomly cleaves the 1,4 $\alpha$-Dglucosidic linkages between adjacent glucose units in the linear amylose chain. It is secreted as primary metabolite of microorganisms and its production is a growth-related process (Kammoun et al. 2008). It possesses approximately $25-33 \%$ share of the world's marketable enzymes. Microbial alpha-amylases are the most stable and produced more economically compared to plant and animal alphaamylases (Gupta et al. 2003).

To meet the growing demands of amylase for industrial application, it is necessary to produce the highly efficient enzymes at large scale with reduced production cost (Haq et al. 2003). Submerged fermentation (SmF) has been traditionally used for the production of industrially important enzymes because of the ease of handling and greater control of environmental factors such as temperature and $\mathrm{pH}$. Use of agro-industrial residues as the substrate for the fermentation has growing interests as they are inexpensive energy-rich resources and also eliminates large-scale accumulation of the biomass (Pandey et al. 2000; Ramachandran et al. 2007). Solidstate fermentation has been generally referred useful for agro-residues utilization (Pandey et al. 2000; Babitha et al. 2007; Binod et al. 2007), although most of the commercial processes are based on submerged fermentation. The growth and the enzyme production by the organisms are strongly influenced by medium composition, and hence optimization of the medium components may lead to improved enzyme productivity (Djekrif et al. 2006). 
The main strategy used for optimizing the medium composition is by changing one medium component as a parameter and keeping the others at a constant level (Prajapati et al. 2013). Such optimization studies do not consider the interaction effects among the variables which influence the overall process for the production of a desired metabolite (Silva et al. 2001). Single variable optimization methods are not only tedious, but also can lead to misinterpretation of results, especially because the interaction effects between different factors are overlooked (Wenstet-Botz 2000). Limitations of the single factor optimization can be eliminated by employing response surface methodology (RSM) which is used to explain the combined effects of all the factors in a fermentation process (Elibol 2004). Response surface methodology may be summarized as a collection of experimental strategies, mathematical methods and statistical inference for constructing and exploring an approximate functional relationship between a response variable and a set of design variables.

In the present study, Plackett-Burman design is used for identifying various nutrients as significant variables influencing alpha-amylase production by Bacillus amyloliquefaciens KCP2. The levels of the significant variables are further optimized using response surface methodology.

\section{Materials and methods}

\section{Strain isolation and identification}

Bacterial strain isolated from municipal food waste samples collected from Vallabh Vidyanagar, Gujarat, India, on Luria agar (LA) was screened for amylase production on starch agar plate. Culture was maintained at $4{ }^{\circ} \mathrm{C}$ on Bushnell Hass agar (BHA) slants containing $1 \%$ starch. Bushnell Hass mineral salt solution has the following composition (g/l): $\mathrm{MgSO}_{4} 0.2, \mathrm{CaCl}_{2} 0.02, \mathrm{KH}_{2} \mathrm{PO}_{4} 1.00$, $\mathrm{K}_{2} \mathrm{HPO}_{4} 1.00, \mathrm{NH}_{4} \mathrm{NO}_{3} 1.00$ and $\mathrm{FeCl}_{3} 0.05$ (pH 7.0). Genomic DNA of the bacterial isolate was extracted and the 16S rDNA gene was amplified using the universal primers (F, 5' AGAGTTTGATCCTGGCTCAG 3'; R, 5' GGTTACCTTGTTACAGCTT $3^{\prime}$ ). Amplification was carried out in a thermal cycler (Applied Biosystems) with reaction profile: initial denaturation at $95{ }^{\circ} \mathrm{C}$ for $1 \mathrm{~min}$, followed by 30 cycles of denaturation at $95{ }^{\circ} \mathrm{C}$ for $30 \mathrm{~s}$, annealing at $55{ }^{\circ} \mathrm{C}$ for $45 \mathrm{~s}$, extension at $72{ }^{\circ} \mathrm{C}$ for $45 \mathrm{~s}$ and finally extension at $72{ }^{\circ} \mathrm{C}$ for $5 \mathrm{~min}$. The purified PCR product was sequenced and the phylogenic relationship of the isolate was determined by comparing the sequence data with the existing sequences available through the gene bank database of the National Center for Biotechnology Information (NCBI).
Preparation of inoculum

A volume of $50 \mathrm{ml}$ of nutrient broth taken in a $250-\mathrm{ml}$ Erlenmeyer flask was inoculated with a loop full of cells from a 24-h-old culture and kept at $37{ }^{\circ} \mathrm{C}$ in a rotary shaker. After $18 \mathrm{~h}$ of incubation, an appropriate aliquot of inoculum was added to get one optical density unit in all the experimental flasks.

Enzyme production, extraction and assay procedure

The experiments were performed according to the design matrix (Tables 2, 4) in 250-ml Erlenmeyer flasks containing $5 \mathrm{~g}$ wheat bran as solid substrate and $10 \mathrm{ml}$ of the salt solution to provide the adequate moisture content. After inoculation, all the experimental flasks were incubated under static condition at $37 \pm 2{ }^{\circ} \mathrm{C}$ and were harvested after $72 \mathrm{~h}$ interval followed by the enzyme extraction with $40 \mathrm{ml}$ of $0.05 \mathrm{M}$ phosphate buffer ( $\mathrm{pH} 8.0$ ) on a rotary shaker at $150 \mathrm{rpm}$ for $30 \mathrm{~min}$ at $25{ }^{\circ} \mathrm{C}$. The content was filtered through muslin cloth, centrifuged at $8,000 \mathrm{rpm}$ for $25 \mathrm{~min}$ and the clear supernatant was used for determining alpha-amylase activity, which is expressed as U/gds (Units/ gram dry substrate). The reaction mixture consisted of $1.0 \mathrm{ml}$ of $1 \%$ starch, $0.9 \mathrm{ml} 0.05 \mathrm{M}$ phosphate buffer $(\mathrm{pH}$ 8.0 ), and $0.1 \mathrm{ml}$ of enzyme extract. After $10 \mathrm{~min}$ of incubation at $65{ }^{\circ} \mathrm{C}$, the liberated reducing sugars were estimated by the dinitrosalicylic acid (DNS) method of Miller (1959). The colour developed was read at $560 \mathrm{~nm}$ using a spectrophotometer (Shimadzu UV-160). TLC analysis of products of enzymatic hydrolysis of starch indicated that it is alpha-amylase since the major end product was found to be maltose.

Effect of the $\mathrm{pH}$ and temperature on the enzyme activity and stability

Enzyme produced by the B. amyloliquefaciens $\mathrm{KCP} 2$ was assayed at different temperatures and $\mathrm{pH}$ ranging $30-90{ }^{\circ} \mathrm{C}$ and $4-10$, respectively. Stability of enzyme was tested by incubating in buffers of different $\mathrm{pH}(4-9)$ at $30^{\circ} \mathrm{C}$ up to $180 \mathrm{~min}$ and residual activity was determined after each $10 \mathrm{~min}$ of incubation under standard assay condition. The thermal stability was studied by incubating enzymes at various temperatures $\left(30-90{ }^{\circ} \mathrm{C}\right)$ and residual activity was measured after each $10 \mathrm{~min}$ of interval up to $180 \mathrm{~min}$ under standard assay condition.

Screening of significant variables using Plackett-Burman design

Plackett-Burman design is a powerful technique for screening and evaluating the important variables that 
Table 1 Variables representing medium components used in Plackett-Burman design

\begin{tabular}{llll}
\hline Variables & Medium components & Positive values & Negative values \\
\hline X1 & Dextrose & $1.5 \mathrm{~g}$ & $0.05 \mathrm{~g}$ \\
$\mathrm{X} 2$ & Starch & $1.5 \mathrm{~g}$ & $0.05 \mathrm{~g}$ \\
X3 & Lactose & $1.5 \mathrm{~g}$ & $0.05 \mathrm{~g}$ \\
X4 & Soy bean meal & $1 \mathrm{~g}$ & $0.05 \mathrm{~g}$ \\
X5 & Yeast extract & $1 \mathrm{~g}$ & $0.05 \mathrm{~g}$ \\
X6 & Ammonium sulphate & $1 \mathrm{~g}$ & $0.05 \mathrm{~g}$ \\
X7 & Ammonium nitrate & $1 \mathrm{~g}$ & $0.05 \mathrm{~g}$ \\
X8 & Calcium chloride & $5 \mathrm{mM}$ & $1 \mathrm{mM}$ \\
\hline
\end{tabular}

influences the response (Plackett and Burman 1946). This technique significantly decreases the number of experiments needed to decide the important variables. In the present study, various medium components such as dextrose, starch, lactose, soya bean meal, yeast extract, ammonium sulphate, ammonium nitrate and calcium chloride were investigated as variables using $\mathrm{PB}$ design to identify the components that significantly affected alpha-amylase production. In PB design each selected variable was considered at two levels, high $(+)$ and low $(-)$ as shown in Table 1. Using the selected levels for each variable and three-dummy variable setup with 12 runs of experiment was generated using the software as shown in Table 2. Each row represents a trial, and each column represents an independent (assigned) or dummy (unassigned) variables. The effect of each variable was determined by the following equation:

$E(\mathrm{Xi})=2\left(\Sigma \mathrm{Mi}^{+}-\mathrm{Mi}^{-}\right)$,

where $E(\mathrm{Xi})$ is the concentration effect of the tested variable $\mathrm{Mi}^{+}$and $\mathrm{Mi}^{-}$representing the alpha-amylase production from trials where the variable (Xi) measured was presented at high and low concentrations, respectively. $N$ is the total number of trials, i.e. 12. Experimental error was estimated by calculating the variance among the dummy variables as:

$V_{\text {eff }}=\Sigma\left(E_{d}\right)^{2} / n$,

where $V_{\text {eff }}$ is the variance of the effect of level, $E_{d}$ is the effect of the level for the dummy variables and $n$ is the number of dummy variables used in the experiment. The standard error (SE, Es) of concentration effect was the square root of variance of an effect, and the significance level ( $P$ value) of each concentration effect was determined using the Student's $t$ test.

$t(\mathrm{Xi})=E(\mathrm{Xi}) / \mathrm{Es}$,

where $E(\mathrm{Xi})$ is the effect of variable $\mathrm{Xi}$.

Response surface methodology

The concentration of the medium components found as a significant variable and the interaction effects between them which may influence the alpha-amylase production significantly were analysed and optimized by response surface Central Composite design (CCD). RSM is useful for small number of variables (up to five) but is impractical for large number of variables, due to high number of experimental runs required. In the present study, concentrations of the three major medium components, starch, ammonium sulphate and calcium chloride (identified by Plackett-Burman design) were optimized, keeping temperature, $\mathrm{pH}$, moisture and inoculum size constant.

According to the design, the total number of treatment combinations is $2^{k}+2 k+$ no, where $k$ is the number of

Table 2 Design matrix and experimental results of Plackett-Burman design

\begin{tabular}{|c|c|c|c|c|c|c|c|c|c|c|c|c|}
\hline \multirow[t]{2}{*}{ Run no. } & \multicolumn{11}{|c|}{ Components } & \multirow{2}{*}{$\begin{array}{l}\text { Alpha-amylase } \\
\text { production (U/gds) }\end{array}$} \\
\hline & $\mathrm{X} 1$ & $\mathrm{X} 2$ & $\mathrm{X} 3$ & $\mathrm{X} 4$ & $\mathrm{X} 5$ & X6 & X7 & $\mathrm{X} 8$ & D1 & D2 & D3 & \\
\hline 1 & 1 & 1 & -1 & 1 & 1 & 1 & -1 & -1 & 1 & 1 & -1 & 9.334 \\
\hline 2 & -1 & 1 & 1 & -1 & 1 & 1 & 1 & -1 & -1 & -1 & 1 & 0.502 \\
\hline 3 & 1 & -1 & 1 & 1 & -1 & 1 & 1 & 1 & -1 & -1 & -1 & 3.702 \\
\hline 4 & -1 & 1 & -1 & 1 & 1 & -1 & 1 & 1 & -1 & -1 & -1 & 12.746 \\
\hline 5 & -1 & -1 & 1 & -1 & 1 & 1 & -1 & 1 & 1 & 1 & -1 & 16.474 \\
\hline 6 & -1 & -1 & -1 & 1 & -1 & 1 & 1 & -1 & 1 & 1 & 1 & 9.308 \\
\hline 7 & 1 & -1 & -1 & -1 & 1 & -1 & 1 & 1 & 1 & 1 & 1 & 21.73 \\
\hline 8 & 1 & 1 & -1 & -1 & -1 & 1 & -1 & 1 & -1 & -1 & 1 & 10.26 \\
\hline 9 & 1 & 1 & 1 & -1 & -1 & -1 & 1 & -1 & 1 & 1 & -1 & 5.50 \\
\hline 10 & -1 & 1 & 1 & 1 & -1 & -1 & -1 & 1 & 1 & 1 & 1 & 19.17 \\
\hline 11 & 1 & -1 & 1 & 1 & 1 & -1 & -1 & -1 & -1 & -1 & 1 & 27.63 \\
\hline 12 & -1 & -1 & -1 & -1 & -1 & -1 & -1 & -1 & -1 & -1 & -1 & 39.05 \\
\hline
\end{tabular}

D1-D3 represent dummy variables 
Table 3 Experimental range and levels of the independent variables of selected components used for response surface Central Composite design

\begin{tabular}{|c|c|c|c|c|c|c|c|}
\hline \multirow[t]{2}{*}{ Variables } & \multirow[t]{2}{*}{ Components } & \multirow[t]{2}{*}{ Range } & \multicolumn{5}{|c|}{ Levels of variable studied } \\
\hline & & & $-\alpha$ & -1 & 0 & +1 & $+\alpha$ \\
\hline $\mathrm{X} 1$ & Starch (w/w) & $0.01-0.50$ & -0.15 & 0.01 & 0.25 & 0.50 & 0.66 \\
\hline $\mathrm{X} 2$ & $\begin{array}{l}\text { Ammonium } \\
\text { sulphate } \\
(w / w)\end{array}$ & $0.01-0.20$ & -0.05 & 0.01 & 0.10 & 0.20 & 0.264 \\
\hline $\mathrm{X} 3$ & $\begin{array}{l}\text { Calcium } \\
\text { chloride } \\
(\mathrm{mM})\end{array}$ & $0.50-5.00$ & -1.03 & 0.50 & 2.75 & 5.00 & 6.53 \\
\hline
\end{tabular}

independent variables and no is the number of repetition of experiments at the central point. Each factor in the design was studied at five different levels $(-\alpha,-1,0,+1,+\alpha)$ as shown in Table 3. All variables were set at a central coded value of zero. The minimum and maximum ranges of variables were determined on the basis of our previous experiments. The full experimental plan with respect to their values in actual and coded form is presented in Table 4. The alpha-amylase activity was measured in triplicate for all 20 different experimental runs. The enzyme production was analysed by using a second-order polynomial equation, and the data were fitted into the equation by multiple regression procedure. The model equation for analysis is given as:

$Y=\beta_{0}+\sum \beta i \mathrm{Xi}+\sum \beta i i \mathrm{Xi}^{2}+\sum \beta i j \mathrm{XiXj}$,

where $\beta_{0}, \beta i, \beta i i$ and $\beta i j$ represent the constant process effect in total, the linear, quadratic effect of $X i$ and the interaction effect between $\mathrm{Xi}$ and $\mathrm{Xj}$, respectively, for the production of alpha-amylase. Later, an experiment was run using the optimum values for variables given by response optimization to confirm the predicted value and experimental value of enzyme production.

Software and data analysis

The results of the experimental design were analysed and interpreted using Design Expert Version 8.0 (Stat-Ease Inc., Minneapolis, Minnesota, USA) statistical software.

\section{Results}

Identification of the bacterial isolate

A 800-bp size 16S rDNA sequence of the isolate was obtained through PCR amplification and sequencing. The

Table 4 Full experimental Central Composite design with coded and actual level of variables and the response function

\begin{tabular}{|c|c|c|c|c|c|c|c|c|}
\hline \multirow[t]{2}{*}{ Run no. } & \multicolumn{2}{|l|}{$\begin{array}{l}\text { A: starch } \\
\text { w/w }\end{array}$} & \multicolumn{2}{|c|}{$\begin{array}{l}\text { B: ammonium sulphate } \\
\text { w/w }\end{array}$} & \multicolumn{2}{|c|}{$\begin{array}{l}\text { C: calcium chloride } \\
(\mathrm{mM})\end{array}$} & \multicolumn{2}{|c|}{$\begin{array}{l}\text { Alpha-amylase } \\
\text { (U/gds) }\end{array}$} \\
\hline & Actual level & Coded level & Actual level & Coded level & Actual level & Coded level & Observed & Predicted \\
\hline 1 & 0.01 & -1 & 0.01 & -1 & 0.5 & -1 & 49.27 & 48.96 \\
\hline 2 & 0.5 & +1 & 0.01 & -1 & 0.5 & -1 & 46.78 & 46.04 \\
\hline 3 & 0.01 & -1 & 0.2 & +1 & 0.5 & -1 & 48.55 & 48.78 \\
\hline 4 & 0.5 & +1 & 0.2 & +1 & 0.5 & -1 & 42.77 & 41.82 \\
\hline 5 & 0.01 & -1 & 0.01 & -1 & 5 & +1 & 51.08 & 52.78 \\
\hline 6 & 0.5 & +1 & 0.01 & -1 & 5 & +1 & 46.86 & 47.39 \\
\hline 7 & 0.01 & -1 & 0.2 & +1 & 5 & +1 & 60.01 & 61.48 \\
\hline 8 & 0.5 & +1 & 0.2 & +1 & 5 & +1 & 51.21 & 52.06 \\
\hline 9 & -0.15 & $-\alpha$ & 0.105 & 0 & 2.75 & 0 & 54.88 & 53.40 \\
\hline 10 & 0.66 & $+\alpha$ & 0.105 & 0 & 2.75 & 0 & 42.60 & 43.02 \\
\hline 11 & 0.255 & 0 & -0.05 & $-\alpha$ & 2.75 & 0 & 46.95 & 46.60 \\
\hline 12 & 0.255 & 0 & 0.26 & $+\alpha$ & 2.75 & 0 & 51.10 & 50.37 \\
\hline 13 & 0.255 & 0 & 0.105 & 0 & -1.03 & $-\alpha$ & 45.38 & 46.80 \\
\hline 14 & 0.255 & 0 & 0.105 & 0 & 6.53 & $+\alpha$ & 61.10 & 58.62 \\
\hline 15 & 0.255 & 0 & 0.105 & 0 & 2.75 & 0 & 48.59 & 47.94 \\
\hline 16 & 0.255 & 0 & 0.105 & 0 & 2.75 & 0 & 47.07 & 47.94 \\
\hline 17 & 0.255 & 0 & 0.105 & 0 & 2.75 & 0 & 48.93 & 47.94 \\
\hline 18 & 0.255 & 0 & 0.105 & 0 & 2.75 & 0 & 46.10 & 47.94 \\
\hline 19 & 0.255 & 0 & 0.105 & 0 & 2.75 & 0 & 48.42 & 47.94 \\
\hline 20 & 0.255 & 0 & 0.105 & 0 & 2.75 & 0 & 48.34 & 47.94 \\
\hline
\end{tabular}


Fig. 1 Phylogenetic relationship on the basis of homology index for a bacterial isolate B. amyloliquefaciens $\mathrm{KCP} 2$

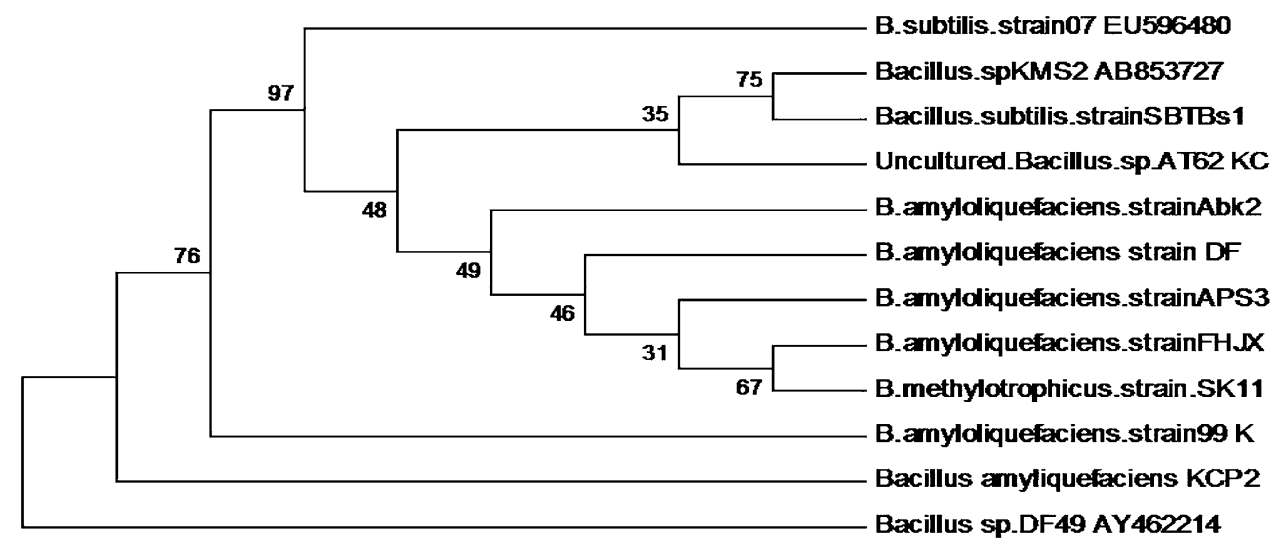

sequence was subjected to a multiple sequence alignment using the BLAST programme of NCBI. The sequence showed a homology of $99 \%$ with B. amyloliquefaciens. The sequence was deposited in the gene bank of the NCBI (Accession No: KF112071). The phylogenetic tree (Fig. 1) was drawn using bioinformatics software MEGA 4.0 (Tamura et al. 2007) after alignment of the sequences with the Clustal X software.

Activity and stability of alpha-amylase

from B. amyloliquefaciens $\mathrm{KCP} 2$

The alpha-amylase produced by $B$. amyloliquefaciens $\mathrm{KCP} 2$ was assessed at different $\mathrm{pH}$ and temperature ranges and it was observed that the activity was very low at acidic $\mathrm{pH}$, but increase in the $\mathrm{pH}$ led to gradual increase in enzyme activity. The maximum activity of the enzyme was observed at $\mathrm{pH} 8.0$ and was found to be highly stable in alkaline $\mathrm{pH}$ (Fig. 2a, b). The optimum temperature for alpha-amylase activity was found to be $65^{\circ} \mathrm{C}$ and it showed good stability in the temperature range of $30-90{ }^{\circ} \mathrm{C}$. More than $85 \%$ of residual activity was observed in case of temperature ranging from 30 to $70{ }^{\circ} \mathrm{C}$ (Fig. 3a, b).

Screening of significant parameter for alpha-amylase production using Placket-Burman design

A statistical approach has been used to screen the most effective supplement and select their concentration to achieve highest possible alpha-amylase production by $B$. amyloliquefaciens $\mathrm{KCP} 2$ under solid-state fermentation using wheat bran as solid substrate. Usually, initial screening of the ingredients is done to understand the significance of their effect on the product formation and then a few better ingredients are selected for further optimization. Plackett-Burman design was used to screen eight different medium components as carbon and nitrogen sources as a 12-run experiment with two levels of
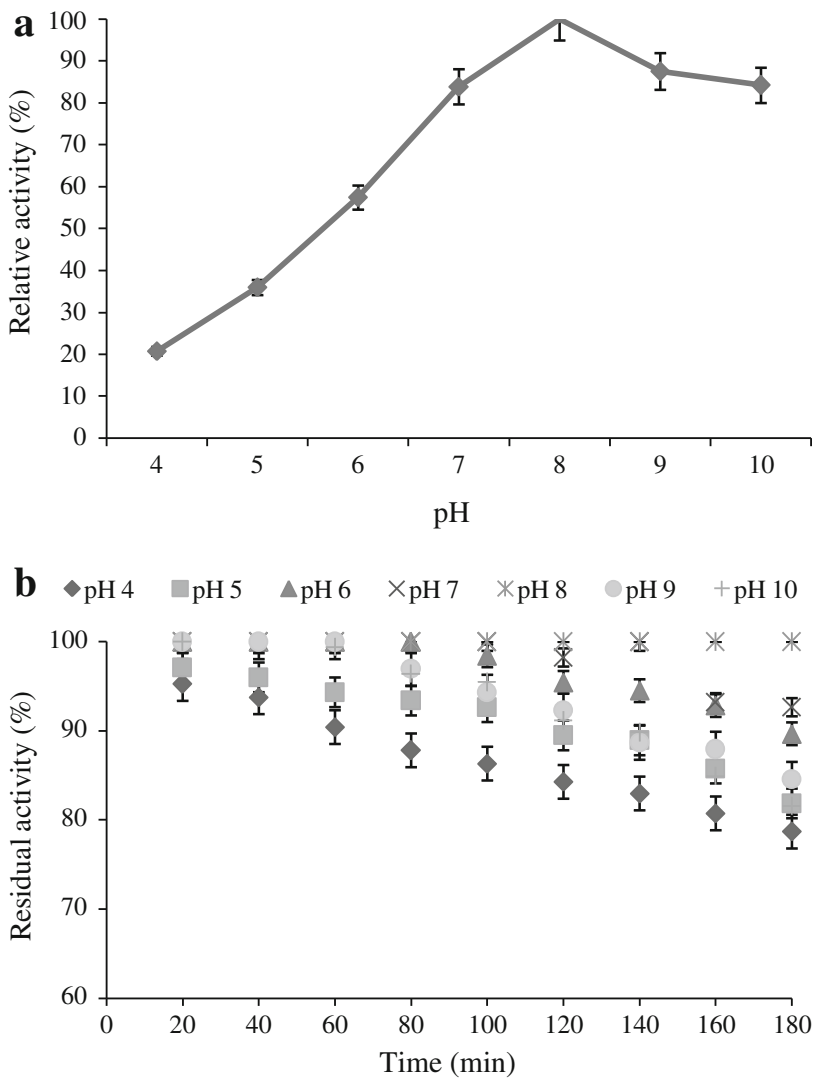

Fig. 2 Effect pH on enzyme activity (a) and stability (b)

concentration of each variable. Studies were carried out under solid-state fermentation at $37{ }^{\circ} \mathrm{C}$ for $72 \mathrm{~h}$. The medium components selected as independent variables and their respective high and low concentrations used in optimization study are presented in Table 1, whereas the Plackett-Burman experimental design followed for the optimization of medium components for alpha-amylase production for 12 trials with two levels of concentration of each variable is given in Table 2 . The variable $\mathrm{X} 1-\mathrm{X} 8$ represented the medium constituents and D1-D3 represented the dummy variable/unassigned variables. The 

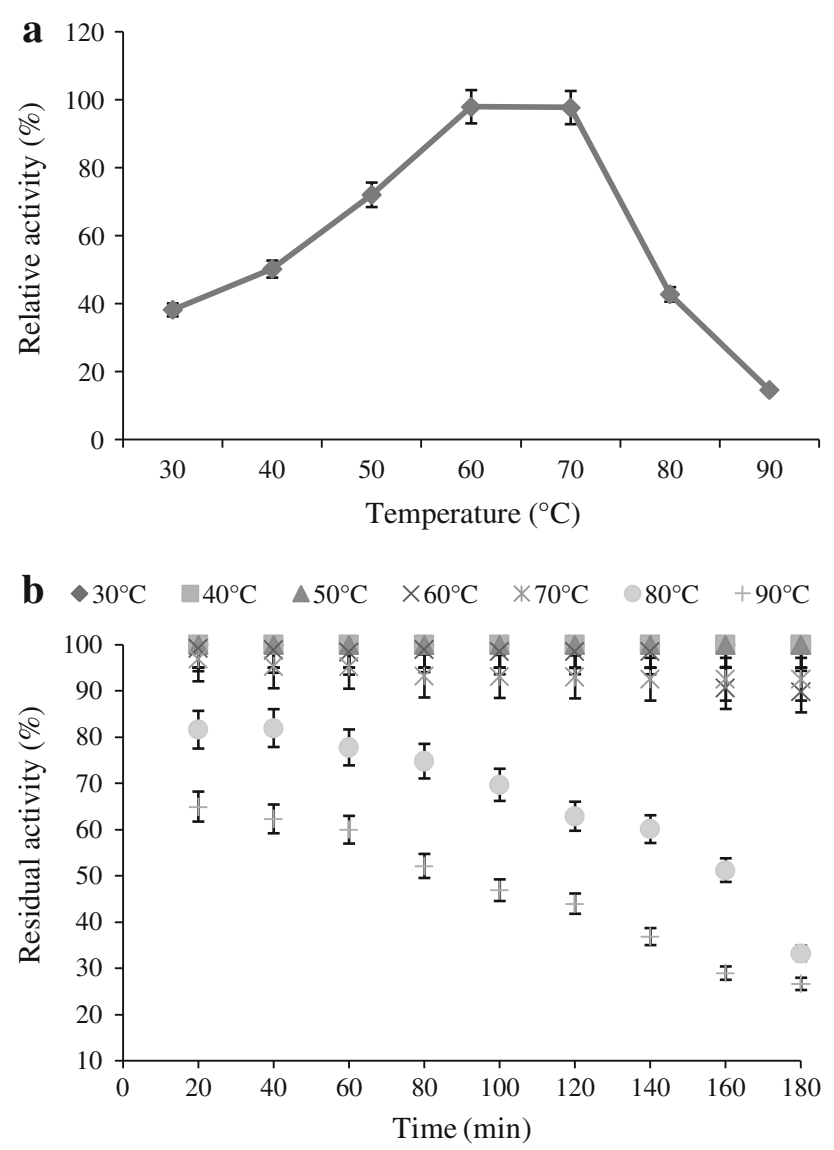

Fig. 3 Effect temperature on enzyme activity (a) and stability (b)

result of Plackett-Burman experiment with respect to amylase production, the effect, standard error, $t(\mathrm{xi}), p$ and confidence level of each component are represented in Tables 2 and 5. The components were screened at the confidence level of $95 \%$ on the basis of their effects. When components show significance at or above $95 \%$ confidence level and its effect is negative, it is considered effective for production but the amount required may be lower than the indicated low $(-1)$ concentration in Plackett-Burman experiment. If the effect is found positive, a higher concentration that the indicated high value $(+)$ concentration is required. In our experiment, starch, ammonium sulphate and calcium chloride gave confidence level $>95 \%$ and could be considered significant and were short-listed for further optimization of their required concentration and their interaction effect leading to maximum enzyme production. Remaining components such as lactose, yeast extract, soya bean meal, ammonium nitrate and dextrose showed confidence level $<95 \%$ and were considered insignificant in the study. The methodology of Plackett-Burman was thus found to be very useful for determination of relevant variables for further optimization.
Table 5 Statistical analysis of components for alpha-amylase production by $B$. amyloliquefaciens $\mathrm{KCP} 2$

\begin{tabular}{lclcll}
\hline Components & Effect & $\begin{array}{l}\text { Standard } \\
\text { error }\end{array}$ & $t$ value & $P$ & $\begin{array}{l}\text { Confidence } \\
(\%)\end{array}$ \\
\hline Dextrose & -3.18 & 1.64 & -1.98 & 0.140 & 85.91 \\
Starch & -10.06 & 1.64 & -6.29 & 0.008 & 99.18 \\
Lactose & -4.90 & 1.64 & -3.06 & 0.054 & 94.53 \\
$\mathrm{NH}_{4} \mathrm{NO}_{3}$ & -1.93 & 1.64 & -1.21 & 0.312 & 68.77 \\
$\mathrm{Yeast} \mathrm{extract}$ & 0.238 & 1.64 & 0.148 & 0.891 & 10.88 \\
$\mathrm{NH}_{4} \mathrm{SO}_{4}$ & -12.71 & 1.64 & -7.94 & 0.004 & 99.58 \\
$\mathrm{CaCl}_{2}$ & -11.40 & 1.64 & -7.12 & 0.005 & 99.43 \\
$\mathrm{Soy} \mathrm{bean} \mathrm{meal}$ & -1.20 & 1.64 & -0.75 & 0.505 & 49.47 \\
\hline
\end{tabular}

Response surface methodology

The Central Composite design was employed to study the interaction among the significant components and also determine their optimal levels. In the present work, experiments were planned to obtain a quadratic model consisting of $2^{3}$ trials. The plan includes 20 experiments and two levels of concentration for each component. In order to study the combined effect of these medium components, experiments were performed at different combinations. Table 4 summarizes the Central Composite experimental plan along with the predicted and observed response for each individual experiment. It shows the production of alpha-amylase (U/gds) corresponding to combined effect of all three components in the specified ranges.

The optimum levels of the selected variables were obtained by solving the regression equation and by analysing the response surface contour and surface plots (Abdelhay et al. 2008). The regression equation obtained after the analysis of variance (ANOVA) provides an estimate of the level of alpha-amylase production as a function of starch, ammonium sulphate, and calcium chloride concentration.

The production of alpha-amylase may be best predicted by the following model:

$$
\begin{aligned}
& \text { Alpha-amylase production }(Y)=(47.94)-(3.08 \times A) \\
& \quad+(1.11 \times B)+(3.51 \times C)-(1.00 \times A \times B) \\
& -(0.61 \times A \times C)+(2.22 \times B \times C)+\left(0.09 \times A^{2}\right) \\
& +\left(0.19 \times B^{2}\right)+\left(1.68 \times C^{2}\right),
\end{aligned}
$$

where $Y$ is alpha-amylase production (U/gds), $A$ is starch concentration (w/w), $B$ is ammonium sulphate concentration (w/w), and $C$ is calcium chloride concentration $(\mathrm{mM})$.

The statistical significance of the second-order model equation was evaluated by $F$ test analysis of variance which revealed that this regression is statistically highly significant for alpha-amylase production. The model 
Table 6 Analysis of variance (ANOVA) for response surface quadratic model of alpha-amylase production from B. amyloliquefaciens KCP2

\begin{tabular}{|c|c|c|c|c|c|c|}
\hline Source & Sum of squares & $d f$ & Mean square & $F$ value & $p$ value & \\
\hline Model & 407.6871 & 9 & 45.29857 & 17.97587 & $<0.0001$ & Significant \\
\hline A-starch & 130.1606 & 1 & 130.1606 & 51.65175 & $<0.0001$ & Significant \\
\hline B-Ammonium sulphate & 17.12545 & 1 & 17.12545 & 6.795908 & 0.0262 & Significant \\
\hline C-Calcium chloride & 168.6796 & 1 & 168.6796 & 66.93727 & $<0.0001$ & Significant \\
\hline $\mathrm{AB}$ & 8.142854 & 1 & 8.142854 & 3.231337 & 0.1025 & \\
\hline $\mathrm{AC}$ & 3.058689 & 1 & 3.058689 & 1.213782 & 0.2964 & \\
\hline $\mathrm{BC}$ & 39.48642 & 1 & 39.48642 & 15.66943 & 0.0027 & Significant \\
\hline$A^{2}$ & 0.12979 & 1 & 0.12979 & 0.051505 & 0.8250 & \\
\hline $\mathrm{B}^{2}$ & 0.54180 & 1 & 0.5418 & 0.215003 & 0.6528 & \\
\hline$C^{2}$ & 40.94109 & 1 & 40.94109 & 16.24669 & 0.0024 & Significant \\
\hline Residual & 25.19965 & 10 & 2.519965 & & & \\
\hline Lack of fit & 19.24826 & 5 & 3.849652 & 3.23425 & 0.1118 & Not significant \\
\hline Pure error & 5.951384 & 5 & 1.190277 & & & \\
\hline Core total & 432.8868 & 19 & & & & \\
\hline
\end{tabular}

CV $3.22 \%$, adequate precision 17.51

$F$ value of 17.98 implies that the model is significant. There is only a $0.01 \%$ chance that a large "Model $F$ value" could occur due to noise. Values of "Prob $>F$ " $<0.05$ indicate that the model terms are significant. In this case $A$, $B, C, B C$ and $C^{2}$ are significant model terms (Table 6). The "lack of fit $F$ value" of 3.23 implies the lack of fit is not significant relative to the pure error. Non-significant lack of fit is good for the model to fit. The $R^{2}$ value (multiple correlation coefficient) closer to 1 denotes better correlation between observed and predicted values. The coefficient of variation $(\mathrm{CV})$ indicates the degree of precision with which the experiments are compared. The lower reliability of the experiment is usually indicated by high value of $\mathrm{CV}$. In the present case, a low CV (3.22\%) denotes that the experiments performed are reliable. Adequate precision measures the signal-to-noise ratio. A ratio $>4$ is desirable. In our case, the ratio is of 17.51 , which indicates an adequate signal. This model can be used to navigate the design space.

The effect of interaction of variables on enzyme (alphaamylase production) yield was studied against any two independent variables while keeping the other independent variables at their constant level. These response surface plots or contour plots can be used to predict the optimal values for different test variables. Therefore, three response surfaces were obtained by considering all the possible combinations. Three-dimensional response plot shown in Fig. 4a describes the behaviour of alpha-amylase production, main effect, interaction effect and squared effect (nonlinear) of starch and ammonium sulphate at different concentrations. Both the components at their lower level did not show any significant effect on the alpha-amylase production. The shape of the response surface curves showed a moderate interaction between these tested variables. Increase in the starch concentration leads to gradual decrease in the enzyme production, while increase in the ammonium sulphate concentration results in the significant increase in the alpha-amylase production. Figure $4 \mathrm{~b}$ depicts three-dimensional curve and contour plot of the calculated response surface from the interaction between starch and calcium chloride while keeping fixed concentration of ammonium sulphate. The level of the calcium chloride in the production medium showed prominent effect on the alpha-amylase production. Increase in the calcium chloride concentration leads to concomitant increment in the alpha-amylase yield, while both components at their lower level did not result in the higher enzyme yield. Figure $4 \mathrm{c}$ depicts the interaction of ammonium sulphate and calcium chloride where the shape of the response surface indicates positive interaction between these two factors. The enzyme yield was found to increase with simultaneous increase in concentration of both the components. Both the components at their lower level did not show any significant effect on the enzyme yield.

\section{Validation of the quadratic model}

Validation was carried out under conditions predicted by the response surface model. The optimal concentrations estimated for each variable were $0.01 \mathrm{~g}$ starch, $0.2 \mathrm{~g}$ ammonium nitrate and $5 \mathrm{mM}$ calcium chloride per $5 \mathrm{~g}$ of wheat bran. The predicted alpha-amylase production obtained from the model using the above optimum concentration of medium components was $61.48 \mathrm{U} / \mathrm{gds}$. To 


\section{$\mathbf{a}$}

Design-Expert@ Software alpha amylase productign Points
- Design

$\prod_{42.6022}^{\circ 1.1}$

$\mathrm{X} 1=\mathrm{A}:$ strach

$X_{1}=A:$ strach
$X_{2}=B$ : mmonium sulhate

Actual Factor
C: Calcium chloride $=2.75$

b

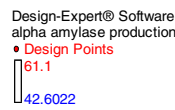

$\prod_{42.6022}^{61.1}$

$X_{1}=A:$ strach
$X_{2}=$ C: Calcium chloride

Actual Factor

B: mmonium sulhate $=0.11$

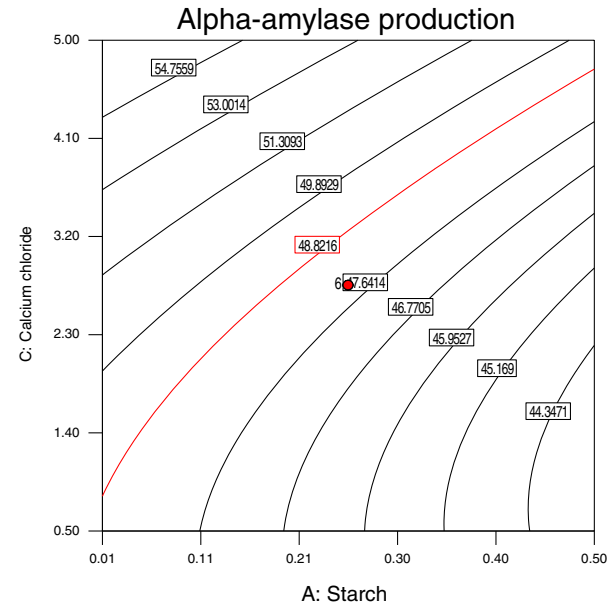

\section{c}

Design-Expert $\circledast$ Software alpha amylase productio - Design Po 61.1

42.6022

$\mathrm{X} 1=\mathrm{B}:$ mmonium sulhate $\mathrm{X}_{2}=\mathrm{C} \cdot$ Calcium chloride Actual Factor A: strach $=0.26$
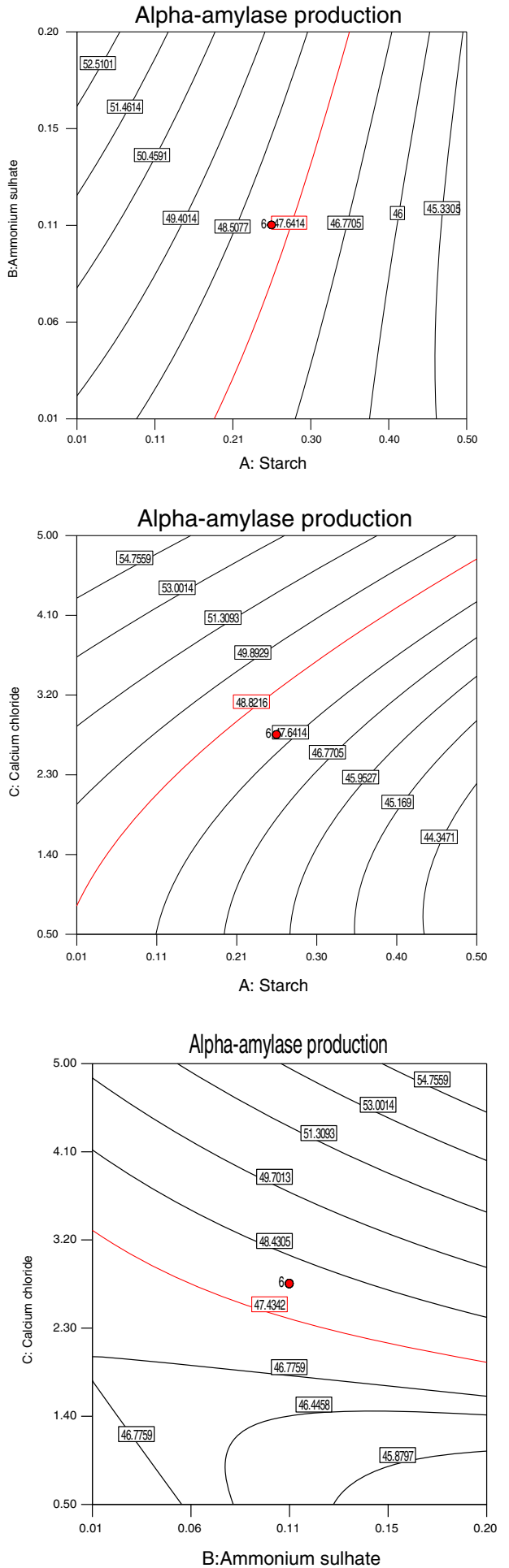

Design-Experr® Softwar
alpha amylase productio

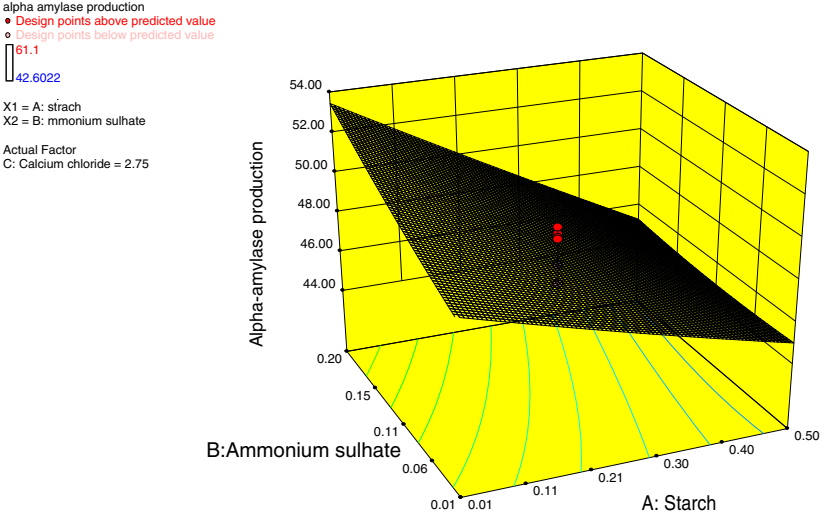

$\prod^{61.1}$

$X_{1}=A:$ stis

Actual Factor

\section{Design-Expertø Software}

alpha amylase production
- Design points above predicted value

- Desiar points above predicted value

$\prod^{61.1}$

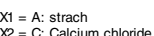

Actual Factor
B: mmonium sulhate $=0.11$

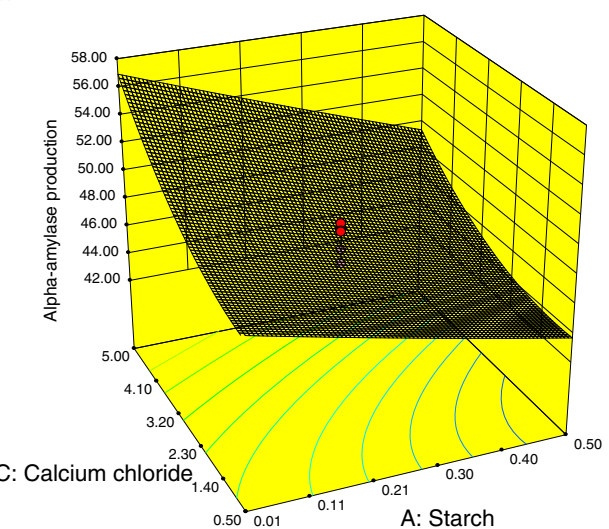

Design-Expert@ Software

a Design points above predicted value
and

$\prod^{61.1}$

$\mathrm{X} 1=\mathrm{B}$ : mmonium sulhate

$\mathrm{X} 1=\mathrm{B}:$ mmonium sulhate
$\mathrm{X} 2=\mathrm{C}:$ Calcium chloride

Actual Factor

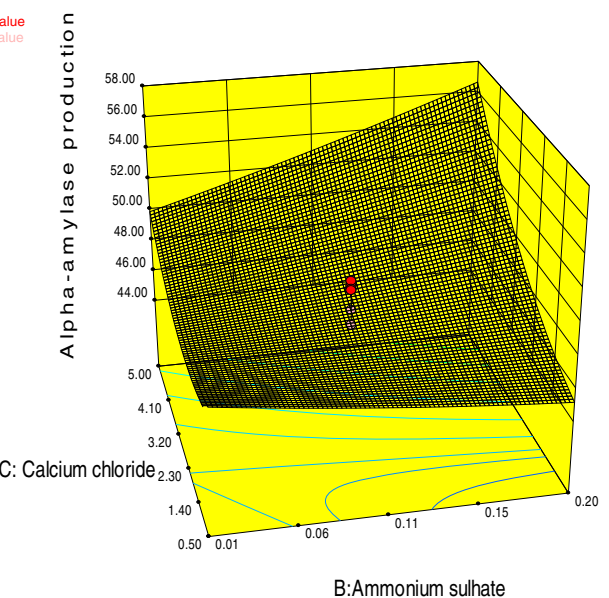

Fig. 4 Response surface graph showing interaction effects between concentration of starch and ammonium sulphate (a), starch and calcium chloride (b), and ammonium sulphate and calcium chloride (c)

validate the prediction of the model, additional experiments in triplicate were performed with the optimized medium. These experiments yielded the maximum amylase activity of $63.12 \mathrm{U} / \mathrm{gds}$. Good agreements between the predicted and experimental results verified the validity of the model and the existence of the optimal points. 


\section{Discussion}

Amylases have several interesting potential application in the food, detergent, pharmaceutical, leather, textile, cosmetic, and paper industries. Still their application in starchbased industries is the major market and thus demand of amylases would always be very high in this sector. There is a constant search for microorganisms producing enzyme with desired properties of $\mathrm{pH}$ and temperature stability considering their industrial application. In this respect the isolate KCP2 was found to have production of enzyme with such properties and was characterized further. As shown in the Fig. 1, the evolutionary history was inferred using the neighbor-joining method (Saitou and Nei 1987). The optimal tree with the sum of branch length of 1.51712318 is shown and the percentage of replicate trees in which the associated taxa clustered together in the bootstrap test (500 replicates) are shown next to the branches (Felsenstein 1985). The evolutionary distances were computed using the maximum composite likelihood method (Tamura et al. 2004) and are in the units of the number of base substitutions per site. Codon positions included were $1 \mathrm{st}+2 \mathrm{nd}+$ $3 \mathrm{rd}+$ non-coding and all positions containing alignment gaps and missing data were eliminated only in pairwise sequence comparisons (pairwise deletion option). There were a total of 1,579 positions in the final dataset.

A marked enhancement in production of alpha-amylase by $B$. amyloliquefaciens in flask fermentation using statistical methods was reported by Zhao et al. (2011). Use of Plackett-Burman design to screen different nutrients affecting production of thermostable $\beta$-amylase and pullulanase by Clostridium thermosulfurogenes SV2 has been reported by Reddy et al. (1999). The substrate employed in the present investigation, i.e. wheat bran, has been reported as a potent substrate for production of alpha-amylase under SSF (Gangadharan et al. 2006; Ramachandran et al. 2004; Mulimani et al. 2000). It is well documented that wheat bran is rich source of carbon and nitrogen, thus supplementation of other nitrogen sources in the medium does not show any significant rise in the enzyme production but sometimes presence of starch as an additional carbon source was found to have inductive effect, and it also has remarkable efficiency in the production of enzyme, being an inexhaustible source of carbon compared to other carbon sources (Prajapati et al. 2013). In the present investigation, apart from starch, lactose was also found to act as an inducer for enzyme production as it gave $94.53 \%$ confidence level during components screening study. Added nitrogen sources also have been reported for an inducing effect for the production of various enzymes including alpha-amylase in an SSF system (Pedersen and Nielsen 2000; Akher et al. 1973). Earlier reports show that among various inorganic nitrogen sources tested, ammonium sulphate, ammonium chloride and ammonium hydrogen phosphate favour growth and enzyme secretion (Narang and Satyanarayana 2001).

Alpha-amylase is an inducible enzyme, which is generally induced in the presence of starch or its hydrolytic product maltose (Rama and Srivastav 1995). Bacillus thermooleovorans preferred starch, glucose, lactose, maltose and maltodextrin as favourable carbon sources for amylase secretion (Narang and Satyanarayana 2001). In some cases, hydrolyzed starch and glucose were found to repress the enzyme yield, which may be due to feedback inhibition caused by the presence of reducing sugars. Easily metabolizable carbohydrates may result in the better growth of the organism along with reduction in the enzyme formation (Rama and Srivastav 1995). The supplementation of metal ions has been reported to provide good growth and also influence higher enzyme yield (Sivaramakrishnan 2006). Most of the alpha-amylase is metalloenzymes and in most of the cases, $\mathrm{Ca}^{+2}$ ions are required for maintaining the spatial conformation of the enzyme, thus play an important role in the enzyme stability and its activity. Amylase from the halophilic Bacillus sp. Strain TSCVKK showed stability at a wide $\mathrm{pH}$ range of $6.5-10.5$ with maximum activity with $\mathrm{pH} 8.0$ suggesting the alkalitolerant nature (Kondepudi and Chandra 2008). Majority of the literature showed that $50{ }^{\circ} \mathrm{C}$ is the optimum temperature for alpha-amylase activity, but in our case we found that $65^{\circ} \mathrm{C}$ is the optimum temperature for the activity of enzyme produced by $B$. amyloliquefaciens $\mathrm{KCP} 2$. Temperature and pH stability of this enzyme justify its alklophilic and thermophilic nature. Statistical approach has also been applied for the production of various enzymes, such as cyclodextrin glucanotransferase (CGTase) (Gawande and Patkar 1999; Mahat et al. 2004), chitinase (Gohel et al. 2005), pectinase (Nair and Panda 1997), vitamin riboflavin (Punjari and Chandra 2000) and glucoamylase (Prajapati et al. 2013).

Present investigation has allowed rapid screening and level optimization of a large number of nutrient parameters influencing thermophilic and alklophilic alpha-amylase production from $B$. amyloliquefaciens $\mathrm{KCP} 2$ using statistical methodology. The results also showed the use of cheap agro-residue as substrate for fermentation, thus contributing to the reduction in cost of production medium. The enzyme yield and the production were found to be significantly influenced by starch, ammonium sulphate and calcium chloride concentration. The data obtained after optimization has resulted in $63.12 \mathrm{U} / \mathrm{gds}$ enzyme production. Even though SSF is widely applied for enzyme production using filamentous fungi, the results of the present study proved that a bacterial isolate such as $B$. amyloliquefaciens $\mathrm{KCP} 2$ can be successfully used for the production of alpha-amylase employing wheat bran within a relatively shorter time interval of 3 days. 
Acknowledgments The authors are grateful to the Department of Biotechnology, Ministry of Sciences and Technology, Government of India, for providing the financial assistance during the course of this investigation.

Conflict of interest We, all authors, declare that this manuscript does not have any financial/commercial conflicts of interest.

Open Access This article is distributed under the terms of the Creative Commons Attribution License which permits any use, distribution, and reproduction in any medium, provided the original author(s) and the source are credited.

\section{References}

Abdelhay A, Magnin JP, Gondrexon N, Baup S, Willison J (2008) Optimization and modeling of phenanthrene degradation by Mycobacterium sp. 6PY1 in a biphasic medium using response surface methodology. Appl Microbiol Biotechnol 78:881-888

Akher M, Leithy MA, Massafy MK, Kasim SA (1973) Optimal conditions of the production of bacterial amylase. Zentralbl Bakteriol Parasitenk Infektionskr Hyg 128:483-490

Babitha S, Soccol CR, Pandey A (2007) Solid-state fermentation for the production of Monascus pigments from jackfruit seed. Bioresour Technol 98:1554-1560

Binod P, Sandhya C, Suma P, Szakacs G, Pandey A (2007) Fungal biosynthesis of endochitinase and chitobiase in solid-state fermentation and their application for the production of $\mathrm{N}$ acetyl-D-glucosamine from colloidal chitin. Bioresour Technol 98:2742-2748

Djekrif DS, Gheribi AB, Meraihi Z, Bennamoun L (2006) Application of the statistical design to the optimization of the culture medium for alpha-amylase production by Aspergillus niger ATCC16404 grown on orange waste powder. J Food Eng 73:190-197

Elibol M (2004) Optimization of medium composition for actinorhodin production by Streptomyces coelicolor A3(2) with response surface methodology. Process Biochem 39:1057-1062

Felsenstein J (1985) Confidence limits on phylogenies: an approach using the bootstrap. Evolution 39:783-791

Gangadharan D, Sivaramakrishnan S, Nampoothiri KM, Pandey A (2006) Solid culturing of Bacillus amyloliquefaciens for alpha amylase production. Food Technol Biotechnol 44:269-274

Gawande BN, Patkar AY (1999) Application of factorial design for optimization of cyclodextrin glycosyltransferase production from Klebsiella pneumoniae AS-22. Biotechnol Bioeng 64:168-172

Gohel V, Jiwan D, Vyas P, Chatpar HS (2005) Statistical optimization of chitinase production by Pantoea dispersa to enhance degradation of crustacean chitin waste. J Microbiol Biotechnol 15:197-201

Gupta R, Gigras P, Mohapatra H, Goswami VK, Chauhan B (2003) Microbial alpha-amylases: a biotechnological perspective. Process Biochem 38:1599-1616

Haq I, Ashraf H, Iqbal J (2003) Production of alpha-amylase by Bacillus licheniformis using an economical medium. Bioresour Technol 87:57-61

Kammoun R, Naili B, Bejar S (2008) Application of a statistical design to the optimization of parameters and culture medium for $\alpha$-amylase production by Aspergillus oryzae CBS 819.72 grown on gruel (wheat grinding by product). Bioresour Technol 99:5602-5609

Kondepudi KK, Chandra TS (2008) Production of surfactant and detergent stable, halophilic, and alkalitolerant alpha-amylase by moderately halophilic Bacillus sp. strain TSCVKK. Appl Microbiol Biotechnol 77:1023-1031

Mahat MK, Illias RM, Rahman RA, Rashid NAA, Mahmood NAN, Hassan O (2004) Production of cyclodextrin glucanotransferase (CGTase) from alkalophilic Bacillus sp. TSI-1: media optimization using experimental design. Enzym Microb Tech 35:467-473

Miller GL (1959) Use of dinitrosalicylic acid reagent for determination of reducing sugar. Anal Chem 31:426-429

Mulimani VH, Patil GN, Ramalingam (2000) $\alpha$-Amylase production by solid state fermentation: a new practical approach to biotechnology courses. Biochem Educ 28:161-163

Nair SR, Panda T (1997) Statistical optimization of medium components for improved synthesis of pectinase by Aspergillus niger. Bioproc Biosyst Eng 16:169-173

Narang S, Satyanarayana T (2001) Thermostable $\alpha$-amylase production by an extreme thermophile Bacillus thermooleovorans. Lett Appl Microbiol 32:31-35

Pandey A, Nigam P, Soccol CR, Singh D, Soccol VT, Mohan R (2000) Advances in microbial amylases. Biotechnol Appl Biochem 31:135-152

Pedersen H, Nielsen J (2000) The influence of nitrogen sources on the alpha amylase productivity of Aspergillus oryzae in continuous cultures. Appl Microbiol Biotechnol 53:278-281

Plackett RL, Burman JP (1946) The design of optimum multifactorial experiments. Biometrika 33:305-325

Prajapati VS, Trivedi UB, Patel KC (2013) Optimization of glucoamylase production by Colletotrichum sp. KCP1 using statistical methodology. Food Sci Biotechnol 22:31-38

Pujari V, Chandra TS (2000) Statistical optimization of medium components for enhanced riboflavin production by a UV mutant of Eremothecium ashbyii. Process Biochem 36:31-37

Rama R, Srivastav SK (1995) Effect of various carbon substrates on $\alpha$-amylase production from Bacillus species. J Microb Biotechnol 10:76-82

Ramachandran S, Patel AK, Nampoothiri KM, Francis F, Nagy V, Szakacs G, Soccol CR, Pandey A (2004) Coconut oil cake-a potential raw material for the production of alpha amylase. Bioresour Technol 93:169-174

Ramachandran S, Singh S, Larroche C, Soccol CR, Pandey A (2007) Oil cakes and their biotechnological applications: a review. Bioresour Technol 98:2000-2009

Reddy PRM, Reddy G, Seenayya G (1999) Production of thermostable $\beta$-amylase and pullulanase by Clostridium thermosulfurogenes SV2 in solid-state fermentation: screening of nutrients using Plackett-Burman design. Bioproc Biosyst Eng 21:175-179

Saitou N, Nei M (1987) The neighbor-joining method: a new method for reconstructing phylogenetic trees. Mol Biol Evol 4:406-425

Silva CJSM, Roberto IC (2001) Optimization of xylitol production by Candida guilliermondii FTI 20037 using response surface methodology. Process Biochem 36:119-124

Sivaramakrishnan S, Gangadharan D, Nampoothiri KM, Pandey A (2006) $\alpha$-Amylases from microbial sources: an overview on recent developments. Food Technol Biotechnol 44:173-184

Tamura K, Nei M, Kumar S (2004) Prospects for inferring very large phylogenies by using the neighbor-joining method. PNAS 101:11030-11035

Tamura K, Dudley J, Nei M, Kumar S (2007) MEGA4: molecular evolutionary genetics analysis (MEGA) software version 4.0. Mol Biol. doi:10.1093/molbev/msm092

Wenster-Botz D (2000) Experimental design for fermentation media development: statistical design or global random search? J Biosci Bioeng 90:473-483

Zhao W, Zheng J, Wang YG, Zhou H (2011) A marked enhancement in production of amylase by Bacillus amyloliquefaciens in flask fermentation using statistical methods. J Cent South Univ Technol 18:1054-1062 